University of Nebraska - Lincoln

DigitalCommons@University of Nebraska - Lincoln

Educational Psychology Papers and

Publications

Educational Psychology, Department of

May 1998

\title{
The Effects of Conjoint Behavioral Consultation and a Structured Homework Program on Math Completion and Accuracy in Junior High Students
}

\author{
Robin K. Weiner \\ University of Utah \\ Susan M. Sheridan \\ University of Nebraska-Lincoln, ssheridan2@unl.edu \\ William R. Jenson \\ University of Utah
}

Follow this and additional works at: https://digitalcommons.unl.edu/edpsychpapers

Part of the Educational Psychology Commons

Weiner, Robin K.; Sheridan, Susan M.; and Jenson, William R., "The Effects of Conjoint Behavioral Consultation and a Structured Homework Program on Math Completion and Accuracy in Junior High Students" (1998). Educational Psychology Papers and Publications. 61.

https://digitalcommons.unl.edu/edpsychpapers/61

This Article is brought to you for free and open access by the Educational Psychology, Department of at DigitalCommons@University of Nebraska - Lincoln. It has been accepted for inclusion in Educational Psychology Papers and Publications by an authorized administrator of DigitalCommons@University of Nebraska - Lincoln. 
Published in School Psychology Quarterly, 13:4 (1998), pp. 281-309. Copyright (C) 1998 American Psychological Association. Used by permission. "This article may not exactly replicate the final version published in the APA journal. It is not the copy of record." http://www.apa.org/journals/spq/

\title{
The Effects of Conjoint Behavioral Consultation and a Structured Homework Program on Math Completion and Accuracy in Junior High Students
}

\author{
Robin K. Weiner, University of Utah \\ Susan M. Sheridan, University of Nebraska-Lincoln \\ William R. Jenson, University of Utah
}

\begin{abstract}
The effects of conjoint behavioral consultation (CBC) and a structured homework program on math homework completion and accuracy in junior high school students (grades seven through nine) who were at risk for academic failure were investigated. A multiple baseline design across five participants was utilized. Follow-up data were collected approximately one month after CBC was completed, to assess maintenance over time. Four of the five students improved their completion rates during treatment. Accuracy rates increased during treatment, but to a lesser degree. At follow-up, three of the five students maintained or improved gains they made during treatment. One student who had not improved during treatment showed improvement at follow-up. Another student was unable to maintain the gains made during treatment. Strengths and limitations of the study are discussed. Implications for practice and suggestions for future research are also presented.
\end{abstract}

There is substantial support in the literature for promoting the involvement of parents in education (Christenson, Rounds, \& Franklin, 1992; Comer \& Haynes, 1991; Epstein, 1987; Hoover-Dempsey, Bassler, \& Brissie, 1987). Several re-

This research was supported in part by grants provided to the second author by the U.S. Department of Education, Office of Rehabilitation and Special Education Services. The opinions expressed herein are those of the authors and do not reflect those of the Department of Education. The study was recognized by Division 16 of the American Psychological Association as the 1997 Outstanding Dissertation, awarded to the first author.

Appreciation is extended to Kevin Fenstermacher for his graphical assistance. Corresponding author: Susan Sheridan, University of Nebraska-Lincoln, Department of Educational Psychology, 220 Bancroft Hall, Lincoln, NE 68588-0345. 
views have documented research indicating multiple benefits to students, including improvements in academic achievement, attitude towards school, aspirations for the future, attendance, maturation, self-concept, and behavior (Christenson et al., 1992; Epstein, 1987; Greenwood \& Hickman, 1991). Parents and teachers also benefit from parent involvement. Research has shown improved teacherparent and child-parent relationships, increased time parents spend with their children, and a more positive attitude toward the classroom and school environments (Clark, 1983; Greenwood \& Hickman, 1991). Typically, parental involvement drops off after elementary school, but continued participation in the home is important for all grade levels (Epstein, 1987).

"Home-school collaboration" is an umbrella term that encompasses a variety of programs concerned with establishing bidirectional relationships between the home and school (Christenson \& Cleary, 1990). In collaborative home-school programs, the responsibility of educating the child (including preventing and remediating academic, social, and behavioral problems) is shared across the home and school systems. Many such programs are designed to address the concerns of both parent and teacher, utilizing collaborative problem solving to resolve concerns, while building a partnership between the home and school.

\section{CONJOINT BEHAVIORAL CONSULTATION}

Conjoint behavioral consultation (CBC; Sheridan \& Kratochwill, 1992; Sheridan, Kratochwill, \& Bergan, 1996) is one vehicle for enhancing partnerships between homes and schools, and may be useful for continuing parental involvement past the elementary grades. It is defined as a "structured, indirect form of service delivery, in which parents and teachers are joined to work together to address the academic, social, or behavioral needs of an individual for whom both parties bear some responsibility" (Sheridan \& Kratochwill, 1992, p. 122). There are four stages of $\mathrm{CBC}$ that structure the problem-solving process: problem identification, problem analysis, treatment implementation, and treatment evaluation (Bergan \& Kratochwill, 1990; Sheridan, Kratochwill, \& Bergan, 1996).

$\mathrm{CBC}$ assumes an ecological perspective and underscores the recognition that children, families, and schools have reciprocal and bidirectional influence over each other. Therefore, the relationship between the home and the school must be collaborative and supportive, to provide maximum benefit to the child. Attention to the mesosystem (i.e., relationship between the central systems in a child's life; Bronfenbrenner, 1977), is paramount.

$\mathrm{CBC}$ encompasses multiple systems and settings in an attempt to increase the understanding of target concerns, improve the effectiveness of interventions, and increase the skills and knowledge of multiple change agents (i.e., consultees). Typically, the CBC consultant works with both the parent and the teacher to provide indirect services to a child client. This affords several advantages for the consulting process: (a) comprehensive and systematic data can be collected at different times and in different settings, (b) consistent use of the intervention may enhance both maintenance and generalization, and (c) multiple treatment agents can monitor the behavioral contrast and side effects of an intervention (Sheridan et al., 1996).

$\mathrm{CBC}$ is a relatively new extension of behavioral consultation, but the research to support its effectiveness is growing (see Sheridan, 1997, for a review). Likewise, the acceptability of CBC to school psychologists across problem types and in comparison to other forms of service delivery appears to be high (Sheridan \& Steck, 1995). Thus far, CBC research has focused on elementary-aged students. Middle school students have not been targeted as a population for CBC research. Some researchers (e.g., Epstein \& Connors, 1995) have described difficulties attaining parent involvement in middle school. However, no empirical studies have been conducted to confirm or dispute the efficacy of $\mathrm{CBC}$ with middle school students. Noteworthy is the finding that school psychologists may question whether CBC is a useful method for delivering service at this level (Sheridan \& Steck, 1995).

\section{HOMEWORK}

Junior high school students experiencing academic difficulties often demonstrate poor homework performance. Literature on the value of homework has shown that homework provides many benefits for student achievement. Keith (1986) reviewed the homework literature and found that time spent doing homework is a critical component that influences achievement from elementary through high school. It can have a significant positive effect on the performance of low income students, and on all students regardless of ability (Keith, 1986).

There are several components to effective homework. First, there should be a clear purpose for the homework, with clear instructions that result in a specific product. Second, homework should be assigned in a way that it can be completed in a reasonable amount of time with at least $80 \%$ accuracy. Third, a variety of types of homework should be utilized. Fourth, it should be assigned regularly. Finally, there should be regular feedback and follow-up on all homework (Olympia, Sheridan, \& Jenson, 1994).

Research on homework interventions fall into three categories-schoolbased, parent training, and self-management. School-based interventions focus on individual and group reinforcement, response cost, and home notes. The use of a teacher-managed individualized program using variable schedules of reinforcement (Rhode, Jenson, \& Reavis, 1992) was found to increase homework completion rates in eight of nine students across two classrooms (Moore, Waguespack, Wickstrom, Witt, \& Gaydos, 1994). Similarly, Malyn (1985) used contingent reinforcement to increase homework compliance, using a "spinner" and invisible ink pen with students in a residential setting.

Parent training has also been used to improve homework compliance in students. Several commercial products are available, including "Winning the Homework War" (Anesko \& Levine, 1987), "Homework without Tears" (Canter \& Hausner, 1987), "Homework Helpers "(Kuepper, 1987), and "Mindmovers: Creative Homework Assignments Grades 3-12” (Hart \& Rechif, 1986). However, 
little information is available on the effectiveness of these programs (Olympia, Sheridan, \& Andrews, 1994).

"Sanity Saver for Parents: Tips for Tackling Homework" (Olympia, Jenson, \& Hepworth-Neville, 1996) is a program designed to help parents create individual homework programs for their children. The program addresses issues regarding assessing homework problem areas, managing environmental variables, implementing motivational programs, establishing appropriate contacts with the school, and setting up a tutoring program. Results of field reviews and pilot testing have suggested that the program is both effective and acceptable to parents and students.

Students have also been trained to improve their homework compliance through self-management. Fish and Mendola (1986) demonstrated the effectiveness of self-management training for increasing homework completion in an elementary special education classroom. Goal setting and contingency contracting have also been shown to improve homework performance in four elementary school students (Miller \& Kelly, 1994). Finally, Olympia, Sheridan, Jenson, and Andrews (1994) demonstrated the efficacy of student managed interventions at increasing homework accuracy and completion.

$\mathrm{CBC}$ can be a useful vehicle for designing and implementing programs promoting a shared responsibility between home and school for homework completion (Olympia, Sheridan, \& Jenson., 1994). Using the CBC framework, the consultant can assist the parent and teacher in: (a) identifying the nature of homework problems, (b) designing an effective plan across settings for increasing time spent on homework, and improving the accuracy and completion rate of the homework, (c) ensuring systematic monitoring and data collection of a homework program's effect on completion and accuracy, (d) determining modifications necessary to improve the homework program, and (e) assessing whether treatment goals have been achieved (Olympia, Sheridan, \& Jenson, 1994; Sheridan \& Kratochwill, 1992).

\section{PURPOSE OF THE CURRENT STUDY}

The purpose of this study was to assess the efficacy of a CBC homework intervention package with parents and teachers of middle school students having difficulty with math homework compliance and accuracy. As such, the intervention was multivariate in nature, involving the actions and interactions of multiple process (i.e., $\mathrm{CBC}$ ) and content (i.e., behavioral homework program) components. Assessments of treatment acceptability, social validity, and intervention integrity were also conducted.

\section{METHOD}

\section{Participants}

Students. Five students (three girls and two boys) from the 8th and 9th grades participated in the study. Participants ranged from 14 to 15 years of age. All were white and raised in middle class families. A sixth student was initially included in the study, but was unable to complete it due to excessive absences. Specifically, $62 \%$ of the data were missing, which precluded the possibility of data interpretation.

Students were selected for inclusion in the study based on several criteria. First, students demonstrated noncompliant behavior in regard to math homework, defined as: (a) returning less than $60 \%$ of homework assignments within the previous two weeks prior to selection, (b) spending less than 15 minutes per night on math homework as measured by self-report, (c) completing an average of $60 \%$ or less of assigned homework for the month prior to selection, as reported by the math teacher, and (d) receiving an average accuracy rate of $60 \%$ or less on assigned homework for the month prior to selection, as reported by the math teacher. Second, the students had no learning disabilities which would prevent them from performing at grade level. None of the students participating in the study appeared to have a significant skill deficit. ${ }^{1}$ However, due to the sporadic and inconsistent nature of their performance and the varied amount of math homework being completed, the participants were not performing at a satisfactory rate. All were failing their math course at the time the study began.

Student 1. Student 1 was a female in the ninth grade. She was the eldest of two girls who lived with both biological parents in a middle class home. She appeared to be an outgoing individual with numerous friends and a busy social life. Her relationship with her parents appeared to be positive, and she willingly offered observations and opinions during the interviews.

Student 1 had experienced problems with math for approximately one year prior to the study. Her teacher indicated that she was capable of doing the work but became easily distracted or frustrated. She often gave up rather than struggling through a difficult problem. This behavior contributed to her difficulties with her math homework. The mother of Student 1 reported that she removed her phone and social privileges when she failed to complete her work.

Student 2. Student 2 was the sixth of seven in his family. He lived with both biological parents in a lower middle class home. He received a diagnosis of Attention Deficit Hyperactivity Disorder (ADHD) prior to the study, but was not receiving medication at his request (i.e., he reported that he was able to focus on tasks and function appropriately without medication).

1. To assess the existence of a skill/performance deficit, student math assignments were subjected to analysis. Specifically, the number of items completed correctly was divided by the total number of items completed and multiplied by 100 to determine whether the problems that students completed were accurate. The results of these calculations indicated that accuracy levels increased markedly when the formula accounted for only items that were completed. In other words, the problems that were being completed tended to be accurate, however, homework scores were diminished by student failure to complete all items. Further, student performance on weekly quizzes tended to hover in the passing range, indicating general knowledge of the content being evaluated. These results suggested the presence of math performance deficits rather than skill deficits. 
Student 2 was a very shy individual. His mother indicated that he had no friends outside the family, and he failed to participate in any extracurricular activities. He appeared to have a functional relationship with both parents and reported being close to all his siblings. Because of his shyness. Student 2 had difficulty participating in the interviews; when asked a direct question he would either remain silent or answer with a "yes" or "no."

The mother of Student 2 and his teacher both agreed that he was capable of completing his math work accurately. However, his mother believed that his symptoms related to ADHD negatively affected both his academic behavior and his social interactions. Student 2 did not complete homework in any subject areas. He was able to pass based on the work he completed in class and his test results. However, both his mother and teacher were concerned that he would continue to have greater difficulty as he progressed through school.

Student 3. Student 3 was the eldest of two daughters. She lived with her mother in a lower-middle class home. Her mother indicated there were some problems regarding trust between herself and her daughter. Student 3 had many responsibilities at home as well as schoolwork. She was a willing and eager participant, and was very verbal during the interviews.

The mother of Student 3 was unaware of her daughter's difficulties in school prior to her involvement in the intervention. She stated that her daughter had had difficulty completing her homework since elementary school. She was allowed to do make-up work to improve her grade, but often failed to do so. Her teacher believed that she was completing work in class but would not turn in her homework.

Student 4. Student 4 was the eldest of two daughters. She was enrolled in eighth grade at the time of the study, although was taking ninth grade algebra. She lived with her mother and stepfather in a middle class home. Her teacher and stepfather agreed that she was intelligent and very capable of doing her work, but that she did not appear to care whether she passed the class. She enjoyed reading and horseback riding, and these privileges were typically taken away when she did not complete her homework. Her parents were not aware of the severity of her situation in her ninth grade algebra class until they began participating in the intervention. During the interviews. Student 4 answered questions when asked but did not volunteer information without prompting.

Student 5. Student 5 was the middle child of three. He lived with both his biological parents in a lower middle class home. His mother was experiencing health problems during the intervention, and was receiving dialysis treatment for kidney failure. He reported having a close relationship with his older sister. He participated in the interviews and volunteered information without prompting.

Student 5 participated in extracurricular school activities revolving around theater. He was participating in a play during the intervention. He had a smal group of close friends and age-appropriate social skills. He had chores at home each night, and he met these responsibilities without any prompting. He often worked on homework in the bedroom of his sister but had difficulty with its completion, reportedly due to lack of motivation.

\section{Consultees and Consultant}

Consultees included the parents and math teachers of the student participants. Parent consultees were four mothers and a stepfather. The average age of the parents was 39 years (range $=33-48$ ). Two math teachers were involved as teacher consultees. One math teacher was responsible for four of the five students (Students 1, 2, 4, and 5). This teacher was male, age 47, had eight years of teaching experience, and had earned an MA degree. The second teacher (responsible for Student 3) was female, age 51, taught for 11 years, and also held an MA degree.

The consultant was a fourth-year female doctoral student in school psychology, trained to mastery in $\mathrm{CBC}$ procedures. The same individual served as the consultant for all $\mathrm{CBC}$ interviews.

\section{SETTING}

The study took place in a suburban public middle school serving primarily lower and middle class families. The specific settings were two math classrooms. Four of the five students (Students 1,2, 4, and 5) were enrolled in a ninth grade algebra class, and Student 3 was in a seventh grade general math class. Consultation interviews were conducted in the teachers' classrooms. Intervention procedures were implemented in the regular classroom setting and in the home.

\section{DESIGN}

A multiple baseline across participants design was used in this investigation. Baseline was initiated for all student-participants simultaneously. Baseline data for Students 1 and 2 were collected five and six days prior to the introduction of treatment. The baseline period for Student 3 was seven days, and 11 days for Students 4 and 5. Interventions were introduced in a staggered fashion across series. Intervention phases were ten days for Student 1; nine days for Student 2; eight days for Student 3; and seven days for Students 4 and 5.

It was originally intended for Students 1 and 2 to serve in one lag, Student 3 in a second lag, and Students 4 and 5 in a third lag. However, scheduling difficulties required a slight delay in the initiation of consultation and resulted in an unscheduled, nonexperimental lag across Students 1 and 2 and across 2 and 3 .

A five-day follow-up was conducted one month after the termination of the CBC homework package intervention. Data were collected on accuracy and completion rates for math homework assignments to determine if homework compliance had been maintained. 


\section{INTERVENTION PROCEDURES}

\section{Conjoint Behavioral Consultation (CBC)}

$\mathrm{CBC}$ is a four stage problem-solving model that includes problem identification, problem analysis, treatment implementation, and treatment evaluation. The consultant and consultees each participated in three CBC interviews: Conjoint Problem Identification Interview (CPII), Conjoint Problem Analysis Interview (CPAI), and Conjoint Treatment Evaluation Interview (CTEI). Each of the interviews was completed in a single session.

Clients (referred students) participated in the CPAI and the CTEI. This was considered important given the age and grade level of the students (i.e., middle school), and the assumption that by increasing the involvement of students their commitment to the intervention program would be enhanced. Their roles included validating information provided by parents and teachers and actively participating in discussions around treatment goals and reinforcers. Students were not involved in CPIIs in order to execute a true baseline period and because of the potential for reactivity based on their knowledge of data collection.

Interviews were scheduled by the consultant with each teacher in person. Once the teacher's schedule was determined, parents were contacted by phone. Each interview was conducted using a standardized set of questions adapted from Sheridan, Kratochwill, \& Bergan (1996), to guide the consultant in attaining equivalent information from all participants. All interviews were audiotaped with the knowledge of the consultees and students.

During consultation, the consultant contacted each consultee weekly either by phone or in person. The purpose of these informal contacts was to assure that the intervention was being properly implemented, to provide support to consultees, and to address any questions or problems that may have arisen.

Consultation sessions were generally conducted in participant pairs. In general, the consultant alternated questions between pairs of consultees. For example, a question regarding a student's work habits was asked of a teacher and parent for one student, and after all relevant information was obtained, the same question was asked in relation to the second student. This format was deemed appropriate and desirable for a number of reasons. First, there were a limited number of teachers involved who were responsible for all participants. Although these teachers were willing to participate in consultation, they were hesitant to engage in up to 12 separate interviews (i.e., given that one teacher had four students in his class, three CBC interviews per student would have yielded 12 separate interviews). This is considered a preconsultation acceptability issue, and presented an opportunity to modify the procedures to match the demands of the middle school setting while maintaining the integrity of the model.

Second, given that homework assignments and expectations were identical across students within classrooms, it was believed that the time costs associated with holding separate interviews per student would have far outweighed the bene- fits obtained by such an approach. In the rare event when separate interviews were held, CBC interviews conducted in pairs lasted an average of $24 \%$ longer than interviews conducted separately. However, because they were conducted in pairs, this brief increase in time per interview resulted in an overall decrease of total time spent in consultation sessions by $34 \%$. In other words, collapsing across interviews and cases, the procedure of pairing consultation participants decreased the time that the teachers and consultant spent in interviews by $34 \%$ compared to the time if interviews had been conducted separately.

Conjoint Problem Identification Interviews (CPIIs). Preconsultation informal interviews and selection procedures yielded sufficient information indicating that the primary issues for all participants involved homework completion and accuracy. The first interview, Conjoint Problem Identification Interview (CPII), therefore, was conducted to confirm and validate the main concerns of parents and teachers. The CPIIs for Students 1 and 2 were conducted together. The CPII for Student 3 was conducted with another student who did not complete the study. Students 4 and 5 participated in individual CPIIs due to scheduling conflicts for the parents. CPIIs lasted between 60 and 90 minutes.

The primary concern of all teacher and parent consultees was the poor math performance of student participants. Specifically, teachers reported failing or near failing grades for all students, due to low homework completion and accuracy percentages. Thus, homework completion and accuracy were determined to be a relevant and appropriate target behavior. Homework was defined as any assigned math problems not completed by students by the end of the school day, that could be completed in a 20-minute time period at home.

Environmental factors affecting homework compliance were discussed in the form of a functional analysis during each CPII. The functional analysis addressed possible antecedents, consequences, and sequential events that might have been contributing to the lack of work completion and accuracy. Parents and teachers were asked during baseline to attend to behaviors, individuals, and other environmental conditions that may have been interfering with math homework compliance. Parents were also asked to complete, with their child, a "Homework Situations Questionnaire" (Olympia et al., 1996) to identify primary areas of homework difficulty and provide a more complete functional analysis of each student's homework behaviors.

Baseline data collection procedures were discussed during the CPII. Parents were asked to monitor unobtrusively the amount of time their child appeared to be spending on homework each night, and a "homework tracking sheet" was provided to write down the time math homework was begun and completed, as well as other pertinent environmental information. Teachers were asked to calculate the completion and accuracy of math homework assignments.

Conjoint Problem Analysis Interviews (CPAIs). Conjoint Problem Analysis Interviews (CPAIs) included the consultant, the consultees (i.e., parent and math teacher), and the student. The CPAIs were conducted in pairs for Students 4 and 5 . 
Table 1. Conditions Surrounding Students' Homework Behaviors

\begin{tabular}{|c|c|c|c|c|}
\hline \multirow[b]{2}{*}{ Student } & \multicolumn{3}{|c|}{ Setting Events } & \multirow[b]{2}{*}{ Consequences } \\
\hline & Location & Time & Distractors & \\
\hline 1 & Kitchen table & Before dinner & Phone calls & $\begin{array}{l}\text { Telephone and social } \\
\text { privileges removed }\end{array}$ \\
\hline 2 & Kitchen table & $\begin{array}{l}\text { No structured time; } \\
\text { commonly } \\
\text { completed after } \\
\text { dinner }\end{array}$ & TV, pets, siblings & None \\
\hline 3 & Kitchen table & Before dinner & Few reported & Variable \\
\hline 4 & Kitchen table & $\begin{array}{l}\text { 5:00-6:00 p.m.; } \\
\text { read for pleasure if } \\
\text { no math homework } \\
\text { was brought home }\end{array}$ & None reported & $\begin{array}{l}\text { Social privileges } \\
\text { removed }\end{array}$ \\
\hline 5 & $\begin{array}{l}\text { Kitchen table } \\
\text { or sister's bedroom }\end{array}$ & $\begin{array}{l}\text { No structured time; } \\
\text { often completed } \\
\text { after 8:00 p.m. }\end{array}$ & Few reported & $\begin{array}{l}\text { TV and extracurricular } \\
\text { privileges removed; } \\
\text { inconsistently } \\
\text { administered }\end{array}$ \\
\hline
\end{tabular}

At the request of the mother of Student 2, separate CPAIs were conducted for Students 1 and 2, resulting in slight, uninterpretable lags between Students 1 and 2 and 2 and 3. The CPAI for Student 3 was completed with the consultees of a student who did not complete the study. CPAIs lasted approximately 45 to 60 minutes.

The purpose of this interview was to evaluate the baseline data and the environmental factors that appeared to be contributing to the math homework noncompliance. Table 1 summarizes specific conditions surrounding each student's homework behaviors. Common problems identified across students were the inconsistency with which they recorded their own homework assignments, and the lack of a structured time and location for completing homework. Although time spent doing homework was initially considered an important variable for improving math accuracy and completion rates, baseline data suggested that time was not a pertinent issue for these students. Review of baseline data revealed a common pattern across students. It appeared that if the students began their homework they tended to work for more than 20 minutes. Students who became frustrated with a difficult problem typically gave up after approximately 30 minutes and stopped working. If the students chose not to do their assignment, they tended not to spend any time working on their math.

During the CPAI, specific strategies and steps for improving students' math homework compliance were reviewed. Information revealed during baseline was highlighted, such as the importance of students recording their assignments and a structured homework time and place. Because students were present during the CPAIs, individualized reinforcement preferences were discussed. Parents were given a homework manual ("Sanity Savers"; Olympia et al., 1996) during the CPAI, to assist in maximizing treatment integrity and creating an appropriate environment for homework (Olympia et al., 1996). Parents were also given a treatment plan worksheet during the CPAI that reviewed the consultation goals, outlined the intervention steps, and provided a matrix on which parents could selfrecord adherence to each intervention step. These forms were intended to increase and help assess the integrity of intervention implementation.

Conjoint Treatment Evaluation Interviews (CTEIs). The final interview, the Conjoint Treatment Evaluation Interview (CTEI), was conducted to assess the effects of the treatment on math homework compliance, and to discuss modifications and maintenance. The CTEI was conducted approximately two weeks after the intervention was introduced. The consultant, the parent, the teachers, and the students were all present. In addition to evaluating the effectiveness of treatment, termination of the consultation process was addressed. CTEIs were conducted in pairs for Students 1 and 2 and for 3 and 4, and all lasted approximately 35 minutes.

\section{Behavioral Homework Intervention}

The intervention used in this study was a structured homework compliance and behavioral reinforcement program (Olympia et al., 1996) implemented across the classroom and home settings. The intervention program was consistent across students to maximize control of extraneous factors and allow for experimental analysis. However, elements were introduced to ensure consistency with the general tenets of consultative problem solving. Specifically, they were presented in a collaborative manner by the consultant, who validated their acceptability with consultees. Likewise, general strategies were presented (e.g., positive reinforcement), but specific plan tactics were determined conjointly, based on individual consultee preferences (e.g., specific homework environments or mode of reinforcer delivery). Consultees were free to add or reject certain intervention tactics as they deemed necessary.

The primary components of the intervention were selected based on empirical support, and included a school component with self-recording, a home program with homework structure and supervision, and positive reinforcement provided across settings. These are presented below.

School Program/Self-Recording. Teachers assigned homework and provided free time (approximately 20 minutes) at the end of each class period that students could use if they chose to complete their daily homework. If they did not complete the assignment in class it became homework for that evening. The length and difficulty of the work assigned was considered to be at a level requiring most students to spend approximately 20 minutes for completion. Therefore, homework was defined as work that was not completed at school, that could be completed within 20 minutes by the average student.

Based on information learned in the CPAIs of all students, organization of homework assignments was problematic. Because assigned work was not re- 
Table 2. Rules for Increasing Homework Compliance at Home

1. Homework should be done in only one place, and preferably not the student's bedroom.

2. Make sure the work space is equipped with appropriate materials for completing homework (i.e., pencils, paper, rulers, etc.).

3. Limit access to the study area during homework time.

4. Keep noise to a minimum during homework time.

5. Start homework at the same time every day.

corded in a systematic way, students often failed to recall specific assignments upon returning home. Therefore, the first intervention step required them to record their math assignment in a day planner. Before leaving the classroom, the teacher initialed the day planners, indicating to students and parents that the recorded assignment was correct. Upon return, teachers corrected the assignments and computed and recorded completion and accuracy percentages. Students were provided with verbal feedback on their completion and accuracy rates from their teacher on a daily basis, and from the consultant on a weekly basis.

Structured Homework Program. Another common factor contributing to homework problems across students was the lack of a structured time and location for completing homework. Therefore, the consultant and consultees agreed upon five rules that parents should follow to increase homework compliance (see Table 2).

Student participants and their parents determined the most appropriate homework time and location, based on their individualized schedules and needs. Parents checked their child's day planner for the assignment at the predetermined homework time and confirmed that the student had begun working on the assignment. Parents were also asked to record the amount of time their child spent on math homework each night, the location in which the homework was completed, and the number of items completed, on a Homework Tracking Sheet. At the end of each night, parents were asked to record those steps of the intervention that they performed.

During the CPAIs, it was determined that students typically should spend at least 20 minutes on their homework assignments. Because of the differences in math levels across classrooms, math homework assignments varied between teachers. The teacher for Students 1, 2, 4, and 5 designed homework using problems from the class textbook. Each assignment was designed to be completed within approximately 20 minutes by an average student. The teacher for Student 3 used her standard homework sheets for assignments and typically assigned one each night. These sheets were also designed to take approximately 20 minutes to complete.

The assignments provided in this study were consistent with those assigned by teachers in their regular classroom routines. That is, teachers regularly de- signed homework that could be completed at a level of approximately $70 \%$ completion and accuracy within 20 minutes by an average student.

Contingent Reinforcement. Reinforcers were determined individually by each student and the consultees during CPAIs. Tangible reinforcers were provided both at home and school. The consultant provided the school reinforcers and the parents provided the home reinforcers.

Nightly reinforcement was contingent upon meeting the criteria of 20 or more minutes spent on the daily assignment and $100 \%$ completion of the assignment. Parents checked their childrens' homework nightly, and determined whether 100\% of the assignment was complete at the end of the homework period. If $100 \%$ of the assignment was complete, the student was to receive a small reinforcer (e.g., candy, food, small items) agreed upon with their parent.

Weekly reinforcers for work completion were provided by the consultant and delivered by classroom teachers via a lottery system. Specifically, the consultant purchased (with the assistance of external support monies) reinforcers such as gift certificates for pizza, music, and movies. Teachers were responsible for conducting the lottery system, which entailed the attainment of tickets to be placed in an envelope if homework was returned on the day it was due. Each day students returned math homework on time, their name was written on a ticket and placed into an envelope. Names were placed into envelopes according to pairings of students as they were involved in $\mathrm{CBC}$ interviews. At the end of each week, a ticket was pulled from the envelopes and the student whose name appeared on the tickets received a reinforcer. Because students were paired for the lottery, there was a $50 \%$ chance of having their name drawn from the envelope and receiving the weekly reinforcer if each student returned $100 \%$ of their homework.

Long-term reinforcers were delivered by parents and contingent upon overall accuracy percentages. A $70 \%$ or greater average accuracy percentage on math homework assignments was required to earn the long-term reinforcer determined during the CPAI. Examples of long-term reinforcers included shoes, horseback riding, and escape from chores. Each student selected a long-term reinforcer at the beginning of the intervention. Each parent agreed to provide the reinforcer if their child's accuracy averaged $70 \%$ or greater at the end of the intervention.

\section{INSTRUMENTATION AND DEPENDENT MEASURES}

\section{Homework Completion and Accuracy}

Homework completion was determined by calculating the number of problems completed divided by the number of problems assigned, multiplied by 100 Accuracy was defined as the number of problems completed correctly divided by 
the total number of assigned problems, multiplied by 100 . Completion and accuracy percentages were calculated each night by the classroom teacher. Calculations were collected for baseline, treatment, and follow-up.

\section{Consumer Satisfaction}

Various forms of consumer satisfaction were assessed in this study. Consultees' perceptions of the consultant's effectiveness was assessed using the Consultant Evaluation Form (CEF; Erchul, 1987), a 12-item, 7-point rating scale with possible responses ranging from "strongly agree" (7) to "strongly disagree" (1). Factor analyses with the CEF indicate that the majority of items measure two general factors: consultant usefulness, and consultant professional manner. Descriptive data obtained on the CEF, based on 85 consultants located at four different universities, yield a mean of 74.5, standard deviation of 11.3 , and coefficient alpha of .95 (Erchul \& Chewning, 1990).

Teachers and parents also completed the Behavior Intervention Rating Scale (BIRS) (Elliott \& Von Brock Treuting, 1991; Von Brock \& Elliott, 1987) and students completed the Children's Intervention Rating Profile (CIRP) (Win \& Elliott, $1985)$ to assess the acceptability of the homework intervention program among the participants. These scales are comprised of 24 and 7 items, respectively. BIRS items are rated on a scale of 1 to 6 and CIRP items are rated on a scale of 1 to 5 . Finally, consultees completed a revised version of the BIRS to assess their acceptability of the CBC procedures.

In a study designed to assess the reliability and construct validity of the BIRS, Von Brock and Elliott (1987) reported alpha coefficients of .97 for the total scale, and $.97, .92$, and .87 for the acceptability, effectiveness, and time factors, respectively. Pearson coefficients computed between the acceptability and time scales, and the effectiveness and time scales resulted in correlations of $.79, .65$, and .63, respectively, supporting a unique but close relationship between the constructs (Von Brock \& Elliott, 1987). Factor analysis of the CIRP (Witt \& Elliott, 1985) suggested one factor (acceptability), and although this instrument has not been subjected to additional psychometric scrutiny, it is used extensively in clinical practice and field-based research.

\section{Social Validation}

Social validation is an important variable that has taken on considerable importance in applied intervention and consultation studies (Gresham \& Noell, 1993; Kazdin, 1977; Kratochwill, 1985). Social validation can be demonstrated through various means, including subjective evaluation and social comparison (Kazdin, 1977). Subjective evaluation involves assessing the perceptions of behavior change and improvement of the target child by individuals in the child's environment. The BIRS provided this information by assessing parent and teacher responses to selected items that loaded on the BIRS Effectiveness factor. Specifically, responses to Items 18 ("The intervention improved the child's behavior to the point that it did not noticeably deviate from other classmates' behavior"), 22 ("When comparing this child with a peer before and after use of the intervention, the child's and the peer's behavior were more alike after using the intervention"), and 23 ("This intervention produced enough improvement in the child's behavior so that the behavior no longer is a problem") were used to assess parent and teacher subjective beliefs about client outcomes.

Goal attainment scaling (GAS) procedures provided a second form of subjective evaluation to assess parent and teacher perceptions of attainment of consultation goals. Following consultation, parents and teachers reported the degree to which they believed consultation goals were met, using a scale of +2 (goal completely met) to -2 (situation got significantly worse).

Social comparison was a method for determining whether the student was viewed as behaving or performing within parameters considered "normal" in the student's environment. Social comparison involved comparing the target student to a socially acceptable standard of performance in math class as determined by the teachers (i.e., a passing grade of $70 \%$ average or better). The student math homework assignments were scored for completion and accuracy. A percentage equaling $70 \%$ (which was considered an average grade) or greater during treatment was considered socially relevant.

\section{Treatment Integrity}

Two forms of treatment integrity were assessed in this research. First, audiotapes of the $\mathrm{CBC}$ interviews were coded by trained observers to assess the integrity with which $\mathrm{CBC}$ procedures were conducted, using a standardized behavioral consultation checklist (Kratochwill \& Bergan, 1990) modified to reflect $\mathrm{CBC}$ procedures. Interrater reliability was calculated for $33 \%$ of a randomly selected representative sample of the $\mathrm{CBC}$ interviews, coded by two observers. Percent agreement was calculated to determine reliability between the observers.

Second, self-monitoring checklists were used by the consultees in this study to assess the integrity with which they completed the primary steps of the intervention. Parents received a checklist on which five essential steps of the homework program were identified: (a) check and initial nightly assignments; (b) ensure an appropriate homework environment (see Table 2); (c) complete homework tracking sheet, reporting the time the student spent on math homework; (d) calculate completion of problems; and (e) provide reward when appropriate. Parents were asked to complete the checklists daily and to return them at the end of treatment. The consultant also contacted the parents by phone each week, to answer any questions about the intervention, maximize treatment integrity, and encourage 
data collection. Teachers were asked to record the names of students who turned in their homework on time, to record accuracy and completion percentages, and to provide the weekly reinforcement.

\section{DATA ANALYSIS PROCEDURES}

Behavioral data were evaluated using visual analyses that included inspection of condition level change and effect sizes, immediacy of change, and level stability. $^{2}$

\section{Level Change and Effect Size}

Condition level was computed for completion and accuracy by adding the percentages for each assignment within each condition and dividing by the total number of data points within that condition (completion and accuracy levels were computed separately). Level change was assessed by investigating the mean of both baseline and treatment conditions and determining whether the mean had increased or decreased.

Effect sizes were computed using a "no assumptions" approach (Busk \& Serlin, 1992) that computes effects without assumptions regarding population distributions or homogenity of variance. In this approach, the differences in phase means were divided by the standard deviation of the baseline, producing a quantitative index of treatment effects.

\section{Immediacy of Change}

The immediate strength or impact of the intervention was investigated by computing the difference between the ordinate value of the first treatment data point and the last baseline data point for each participant (Tawney \& Gast, 1984). In general, the larger the difference the greater the magnitude of sudden change associated with intervention implementation.

\section{Level Stability}

Level stability was assessed in two ways. First, the mean level of a condition was calculated and a mean line was drawn parallel to the abscissa (X axis) at the value level. Data were considered stable if $80 \%$ to $90 \%$ of the data points fell within a $15 \%$ range of the mean level. A stability criterion of $20 \%$ was used

2. The computation of percentage of nonoverlapping data (PND) between phases was considere as an additional means of data evaluation. However, Scruggs, Mastropieri, and Casto (1987) discourage its use with highly variable baseline data (one defining characteristic of participants in this study), and in cases where ceiling effects are evident. Because such patterns were present in this data set, PND was deemed an inappropriate metric to evaluate outcome.

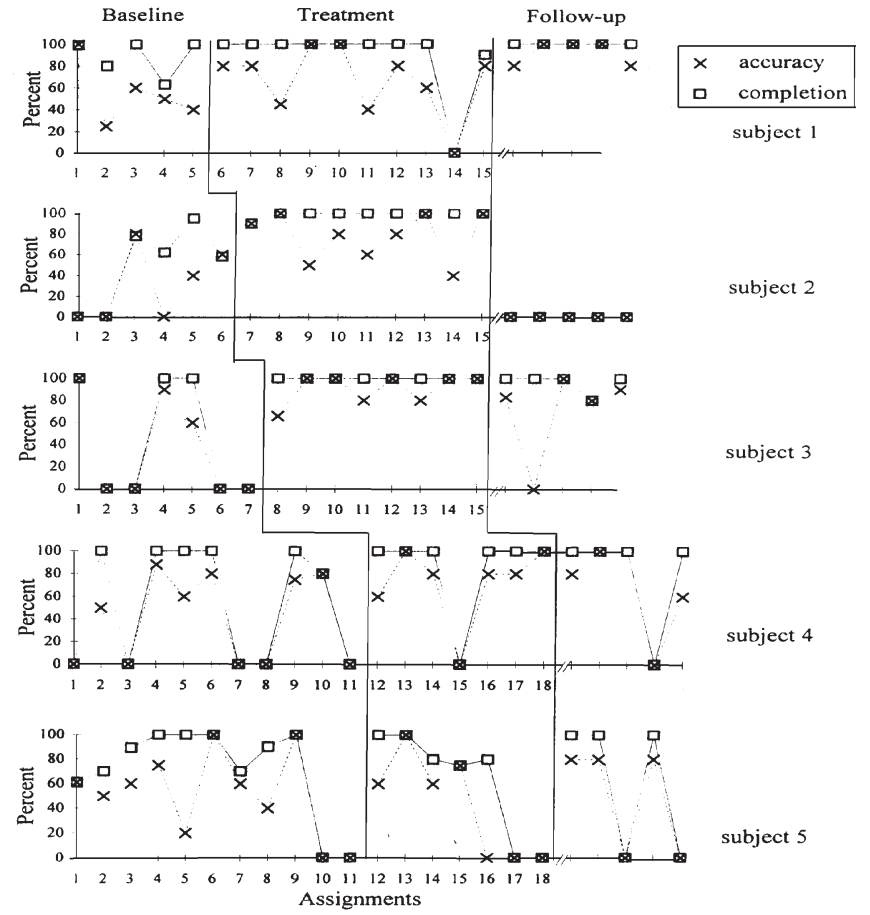

Figure 1. Percent of math homework completion and accuracy per student across experimental phases.

in phases wherein participants had fewer opportunities to respond (i.e., fewer than five data points per phase; Tawney \& Gast, 1984). Second, within phase standard deviations were calculated for each student. The smaller the standard deviation, the less variability among data.

\section{Descriptive Data}

Additional data were collected to assess consumer satisfaction, social validity, and treatment integrity. These data are reported descriptively.

\section{RESULTS}

Behavioral data for homework completion and accuracy collected during baseline, treatment, and follow-up across students are provided in Figure 1 Likewise, Tables 3 and 4 present the mean completion and accuracy rates and effect sizes for all students across all phases of the study (baseline, treatment, and follow-up). 
Table 3. Students' Average Rates, Standard Deviations, and Effect Sizes of Math Completion

\begin{tabular}{lccccccc}
\hline Student & \multicolumn{2}{c}{ Baseline } & \multicolumn{2}{c}{ Treatment } & Effect Size & \multicolumn{2}{c}{ Follow-Up } \\
\hline 1 & 87 & $(16.56)^{\mathrm{a}}$ & 89 & $(31.42)$ & .12 & 100 & $(0)$ \\
& & & $99^{\mathrm{b}}$ & $(3.33)$ & .72 & & \\
3 & 49 & $(40.12)$ & 99 & $(3.33)$ & 1.25 & 0 & $(0)$ \\
4 & 57 & $(53.45)$ & 100 & $(0)$ & .80 & 96 & $(8.94)$ \\
4 & 53 & $(50.81)$ & 86 & $(37.79)$ & .67 & 80 & $(44.72)$ \\
& & & $100^{\mathrm{b}}$ & $(0)$ & .94 & $100^{\mathrm{b}}$ & $(0)$ \\
5 & 71 & $(37.72)$ & 62 & $(43.57)$ & -.24 & 60 & $(54.77)$ \\
Total & $63.2(39.73)$ & 87.2 & $(22.87)$ & .60 & 67.2 & $(21.69)$ \\
& & & $92^{\mathrm{b}}$ & $(10.05)$ & .72 & $71.2^{\mathrm{b}}$ & $(12.74)$ \\
\hline
\end{tabular}

${ }^{\mathrm{a}}$ Numbers in parentheses reflect the standard deviations within experimental phases.

${ }^{\mathrm{b}}$ Within phase data computed without the outlying data point(s).

\section{Homework Completion}

Student 1. During baseline. Student 1 completed an average of $87 \%$ of her homework (range $=63-100 \%$ ), with a very slight average increase to $89 \%$ (range $\wedge 0-100 \%$ ) during treatment. Visual inspection of the data series reveals that this student's treatment data are unduly influenced by one outlying data point; without this data point, the average completion percentage is $99 \%$ (range $=90-100 \%$ ), with the data yielding an effect size of .72. The outlier represents an assignment given when Student 1 was absent from school, which she failed to make up. One month following the end of treatment. Student 1 continued to complete $100 \%$ of her homework with no variability.

Baseline and treatment data for Student 1 are considered generally variable when all data points are considered. When the outlying data point in the treatment condition is excluded from the analysis, treatment data are highly stable.

Table 4. Students' Average Rates, Standard Deviations, and Effect Sizes of Math Accuracy

\begin{tabular}{|c|c|c|c|c|c|c|c|}
\hline \multirow{2}{*}{$\frac{\text { Student }}{1}$} & \multicolumn{2}{|c|}{ Baseline } & \multicolumn{2}{|c|}{ Treatment } & \multirow{2}{*}{$\begin{array}{c}\text { Effect Size } \\
.39 \\
.64\end{array}$} & \multicolumn{2}{|c|}{ Follow-Up } \\
\hline & 55 & $(28.28)^{a}$ & $\begin{array}{l}66 \\
73^{b}\end{array}$ & $\begin{array}{l}(30.91) \\
(21.47)\end{array}$ & & 92 & $(10.95)$ \\
\hline 2 & 30 & $(35.21)$ & 78 & (22.79) & 1.36 & 0 & $(0)$ \\
\hline 3 & 50 & (46.13) & 91 & (13.48) & .89 & 71 & $(40.2)$ \\
\hline 4 & 39 & $(39.01)$ & $\begin{array}{l}71 \\
83^{b}\end{array}$ & $\begin{array}{l}(34.36) \\
(15.05)\end{array}$ & $\begin{array}{r}.82 \\
1.13\end{array}$ & $\begin{array}{l}68 \\
85^{b}\end{array}$ & $\begin{array}{l}(41.47) \\
(19.15)\end{array}$ \\
\hline 5 & 51 & $(34.53)$ & 42 & $(41.62)$ & -.26 & 48 & $(43.81)$ \\
\hline Total & 45 & $(36.63)$ & $\begin{array}{l}69.6 \\
73.4^{b}\end{array}$ & $\begin{array}{l}(28.63) \\
(22.88)\end{array}$ & $\begin{array}{l}.67 \\
.78\end{array}$ & $\begin{array}{l}55.8^{2} \\
59.2^{\mathrm{b}}\end{array}$ & $\begin{array}{l}(27.94) \\
(22.82)\end{array}$ \\
\hline
\end{tabular}

${ }^{a}$ Numbers in parentheses reflect the standard deviations within experimental phases.

${ }^{\mathrm{b}}$ Within phase data computed without the outlying data point(s).
Student 2. Baseline completion levels for Student 2 averaged $49 \%$ (range $=$ $0-95 \%$ ), with an increase to an average of $99 \%$ during treatment (range $=90$ $100 \%$ ). A $30 \%$ improvement was noted from the end of baseline to the beginning of treatment. Data were quite variable during baseline. However, they became high and stable during treatment, with an overall effect size of 1.25. At follow-up, Student 2 failed to complete any homework.

Student 3. The baseline levels of Student 3 for homework completion averaged $57 \%$ (range $=0-100 \%$ ), increasing to a treatment average of $100 \%$ and effect size of .80 . A change in performance was noted immediately, with rates increasing from $0-100 \%$ from the last-baseline point to the first treatment data point. Likewise, baseline completion rates were variable, and they became high and stable during treatment. During follow-up, Student 3 maintained a $96 \%$ completion rate.

Student 4. For Student 4, baseline and treatment completion averages were $53 \%$ and $86 \%$, respectively (range in each condition $=0-100 \%$ ). Similar to Student 1 , visual analysis of this student's data reveals one outlier that unduly effects the treatment average. If excluded from the analysis, the completion rate during treatment increases to $100 \%$, with an effect size of .94 . This data point reflects homework assigned on this student's birthday, which she chose not to complete. The immediacy effect was great; performance increased $100 \%$ from the end of baseline to the beginning of treatment. Data during baseline were variable. However, they became stable during treatment, with the exception of the outlying data point. At follow up, completion decreased slightly to $80 \%$. This figure is diminished due to one assignment not turned in to the teacher. If this outlying data point is excluded from the analysis, the follow up completion rate is maintained at $100 \%$.

Student 5. Homework completion rate for Student 5 averaged $71 \%$ during baseline (range $=0-100 \%) .{ }^{3}$ This student's performance changed in a positive direction immediately upon initiation of the intervention (increasing from $0-100 \%$ between adjacent baseline and treatment data points), possibly due to treatment effects. During treatment, however, completion averaged only $62 \%$ (range $=0$ $100 \%$ ), with a descending trend noted from the beginning to the end of treatment. For both baseline and treatment, data for Student 5 are variable. At follow-up, his completion rate remained at a level equal to treatment, with much variability.

\section{Homework Accuracy}

Student 1. For Student 1, baseline percentages for accuracy averaged 55\% $($ range $=25 \%-100 \%)$, with treatment percentages averaging $66 \%$ (range $=0$ $100 \%$ ). If the outlying treatment data point is excluded from analysis, the average accuracy rate increases to $73 \%$ (range $=40-100 \%$ ), with an effect size of .64 .

3. Screening data for Students 1 and 5 were considerably lower than their respective baseline levels, meeting the $60 \%$ criteria for inclusion. 
A $40 \%$ increase in accuracy was noted between the last baseline data point and the first treatment data point. Data in both baseline and treatment phases were variable. At follow-up. Student 1 improved accuracy even further, with a mean of $92 \%$.

Student 2. For Student 2, accuracy percentages increased from an average of $30 \%$ during baseline (range $=0-80 \%$ ) to $78 \%$ during treatment (range $=40$ $100 \%$ ), yielding an effect size of 1.36 . A $30 \%$ increase was noted from the end of baseline to the beginning of treatment. Neither the baseline nor treatment data were stable. Because Student 2 did not complete any homework during follow-up, his accuracy rate for this phase was 0 .

Student 3. For Student 3, accuracy baseline data averaged 50\% (range $=0$ $100 \%$ ), with an increase to $91 \%$ (range $=66-100 \%$ ) during treatment and effect size of .89. A substantial, immediate treatment effect was indicated from the end of baseline to the beginning of treatment. According to criteria established by Tawney and Gast (1984), neither the baseline nor treatment data were stable for Student 3. This formula underestimates stability when data evidence a ceiling effect, as demonstrated during this student's treatment phase. When considering variance as defined by within-phase standard deviation, Student 3's data appear stable (i.e., a substantial decrease in standard deviation was observed across baseline and treatmen phases, and Student 3's treatment data yielded the lowest standard deviation of all participants). During follow-up, her accuracy rate fell to $71 \%$.

Student 4. The accuracy percentages for Student 4 increased from an average of $39 \%$ at baseline (range $=0-88 \%$ ) to $71 \%$ at treatment (range $=0-100 \%$ ). If the outlying data point is not considered in the analysis, the treatment average for accuracy increases to $83 \%$ (range $=60-100 \%$ ), with an effect size of 1.13 . An immediate effect was evident, with a $60 \%$ increase from the end of baseline to the beginning of treatment. Baseline data for Student 4 are variable. However, the data became stable during treatment, with the exception of the outlier. At follow-up. Student 4 recorded an average accuracy rate of $68 \%$. If the outlying data point is excluded from the calculations. Student 4's follow-up accuracy average increases to $85 \%$

Student 5. Baseline accuracy percentages for Student 5 averaged 51\% (range $=0-100 \%$ ), with treatment data averaging $42 \%$ (range $=0-100 \%)$. Treatment effects were immediate, demonstrating an increase of $60 \%$ from the end of baseline to the beginning of treatment. However, a descending trend was evident for this student's accuracy (largely due to his failure to return homework at the end of the phase). Neither baseline nor treatment data for Student 5 were stable. During follow-up, this student had an average accuracy rate of $48 \%$.

Accuracy Across Students. Similar trends in accuracy data are evident across students. Specifically, dips in accuracy percentages occur in close proximity for Students 1, 2, 4, and 5, who were all in the same math classroom. Accuracy percentages for Students 1 and 2 decline at data point 14; Student 4 accuracy percentage shows a similar decline at data point 15, and Student 5 accuracy percent- age drops at data points 16 through 18 . According to their teacher, data points 14 through 16 represent the introduction of new skills. Student 4 indicated that data point 15 also represented her birthday, and she chose not to complete the assignment for that evening. Student 5 appeared to have difficulty rebounding from the introduction of new skills, as well as an admitted lack of supervision from his mother on data points 17 and 18. These trends, evident with the introduction of new skills over a three-day period, suggest that responses may have been a function of curricular or task-related variables, and not variables inherent to the intervention. This is particularly likely in light of the fact that completion rates continued to remain relatively high during these probes.

\section{Consumer Satisfaction}

Satisfaction measures were collected in various forms. Specifically, consultee perceptions of the effectiveness of the consultant, consultees' acceptability of the consultation procedures, and consultee and client acceptability of the homework intervention program were assessed.

Perceptions of Consultant Effectiveness. The Consultant Evaluation Form $(C E F)$, a 12-item scale rated on a 7-point Likert system, was completed by teachers and parents. Of a possible 84 points, teacher responses yielded a mean of 65 (range $=62-78$; item mean $=5.42)$, and parent responses resulted in a mean of 73.6 (range $=63-81$; item mean $=6.13$ ). This suggests that both teachers and parents perceived the consultant to be generally effective, with parent responses being more favorable.

Acceptability of Homework Intervention. Consultees rated their acceptability of the homework program by completing the Behavior Intervention Rating Scale (BIRS). Items on the BIRS are rated on a 6-point Likert scale, with total possible total scores ranging from 24-144 (high scores reflect a high degree of acceptability). Parent and teacher average acceptability responses yielded means of 130 and 125, respectively (individual item means $=5.4$ and 5.2), suggesting that they found the homework intervention highly acceptable.

Students rated their personal perceptions of the acceptability of the treatment using the Children's Intervention Rating Profile (CIRP). Items on the CIRP are rated on a 5-point scale, with low scores indicating high acceptability. Individual item means across students was 2.6 (neutral), suggesting that the students found the intervention neither favorable nor unfavorable.

Consultee Acceptability of Consultation Procedures. Teachers and parents were asked to rate acceptability of the CBC process using a revised format of the BIRS. Parent acceptability of the consultation procedures resulted in an overall mean of 134 (individual item mean $=5.6$ ), and teacher overall mean score for the consultation procedure was 125 (individual item mean $=5.2$ ). These results indicate that both the parents and the teachers found the consultation procedures highly acceptable. 


\section{Treatment Integrity}

Homework Intervention Integrity. Parents used self-monitoring checklists to assess their perceptions of the degree to which they completed the primary intervention steps. Parental self-monitoring checklists were completed for Students 1,2 , and 3 only. The degree to which these parents reported adherence to the treatment steps averaged $93.6 \%$ (range $=84-100 \%$ ).

Both teachers returned their monitoring sheets with all necessary information included for $100 \%$ of the intervention days (i.e., lists of names of students who turned in their homework, completion and accuracy percentages, and names of students who had received the weekly reinforcers). This suggested that they adhered completely to the homework intervention tactics.

Consultation Integrity. Each interview was audiotaped and coded by trained independent observers to determine the percent of $\mathrm{CBC}$ objectives met by the consultant in the structured interviews. According to these ratings, the consultant met $91 \%$ of CBC objectives. Thirty-three percent of the audiotapes were coded by two raters to determine interrater agreement, which equaled $89 \%$.

Subjective Evaluation. Subjective evaluation of the meaningfulness of consultation and intervention outcomes was assessed using selected items from the BIRS effectiveness factor (items 18,22 , and 23). On a scale of 1 to 6 , the combined consultee ratings for the intervention was 4.84 , and 4.74 for the consultation procedures. These results suggest that parents and teachers found both the consultation and intervention procedures to produce generally meaningful outcomes for students.

A second form of subjective evaluation occurred in the form of Goal Attainment Scaling (GAS) ratings. On a scale of +2 (goal completely met) to -2 (situation got significantly worse), teachers reported that student goals were fully met $($ mean $=2.0)$. Parent ratings on this scale yielded a mean of 1.71 .

Social Comparison. Each student's grade was determined prior to the onset of treatment and at the termination of consultation. Of the five students, three students $(1,3$, and 4$)$ improved from receiving a failing grade to passing with a "B" or "C." Although Students 2 and 5 did not demonstrate a meaningful change in grade, they did show an improvement in their overall grade percentage by $14 \%$ and $23 \%$, respectively.

\section{DISCUSSION}

\section{General Findings}

Improvement in homework completion and accuracy was evident among the majority of students. Averaging across all students, mean increases were evident for both completion and accuracy from baseline to treatment (see Tables 3 and 4). Four of the five participants (Students 1,2,3, and 4) demonstrated an increase in both completion and accuracy means between baseline and treatment. Across these four participants, increases ranged from $2-50 \%$ for completion, and $11^{\wedge} 8 \%$ for accuracy. Only Student 5 failed to show any improvement in the rate of completion and accuracy for his math homework. Although gains did not maintain for all students, overall rates at follow-up reflected improvements over baseline levels.

Experimental control in single subject research is generally demonstrated using criteria related to level change, immediacy, stability, and maintenance of treatment change. A summary of outcomes on these variables is provided in Table 5 . For four of the five students, experimental control for completion is suggested across most variables. For these four students (1, 2, 3, and 4), completion data are generally supportive of positive interpretations across the level change and immediacy variables. Baseline data are variable for all students, but became high and stable for each of these four students (when the two outlying data points are not considered for Students 1 and 4).

Accuracy data showed similar trends for four of the five students. However, accuracy continued to be variable during treatment for most students. This may be due partly to the introduction of new skills for Students 1, 2, 4, and 5 at data points 14-16. It may also reflect some learning gaps evident in these middle school students who had a history of inconsistent and poor performance. It is noteworthy, however, that three of the five students increased their grades from " $F$ " to " $B$ " or "C."

Follow-up data suggest that all participants for whom interpretation is possible, with the exception of Student 2, either maintained or increased their homework completion means during follow-up. Similarly, Students 1 and 4 maintained their improved accuracy means. Social validity data, in the form of grades and subjective ratings, provided promising results. Three of the five students increased from failing to passing grades, and the remaining two students increased their completion and accuracy percentages by the end of the study. Furthermore, all consultees reported that consultation goals were at least partially met. Finally, consultees found both $\mathrm{CBC}$ and the intervention used in the study to be acceptable and effective methods for addressing the issues and concerns of both parents and teachers.

\section{Unexpected Results}

Although generally positive results were obtained in this study, the performances of two students (Students 2 and 5) were somewhat unexpected. Student 2 demonstrated positive gains during treatment, although accuracy continued to be variable and he failed to achieve a passing grade by the end of treatment. This finding is unfortunate because this student appeared to respond well to the structure, supervision, and reinforcement provided during treatment. During weekly contacts, the teacher indicated that Student 2 was staying after class to begin his assignment or to receive extra help. Further, his test scores improved from $14 \%$ to $48 \%$. This student's mother stated over the phone that although he needed remind- 


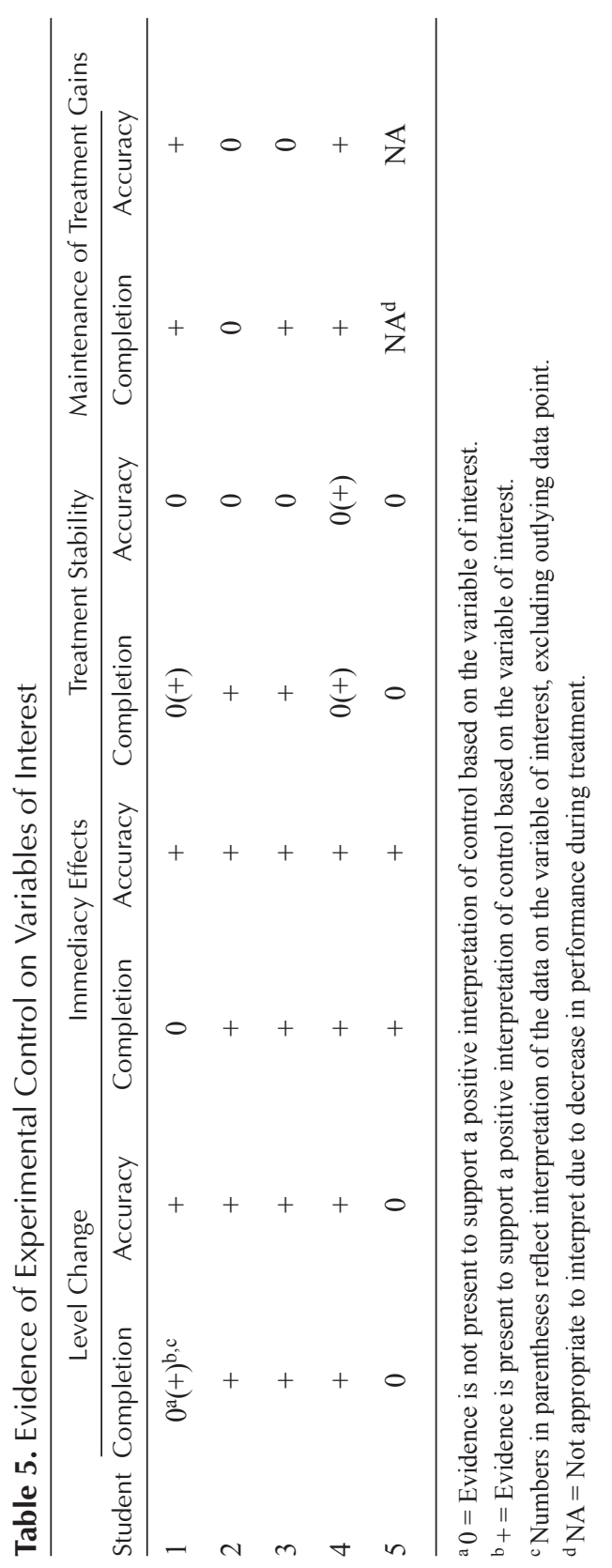

ers to begin his homework, he continued his work without further prompting. Unfortunately, he failed to turn in missing assignments from earlier in the quarter, which prevented his average from increasing to a passing grade.

Student 2 failed to maintain or improve his treatment levels at follow-up. His mother indicated that she had not been able to supervise or reinforce his math homework behavior, and he had lost motivation to complete his math homework on his own. Thus, it appears that the treatment program produced important gains for this student, but it was insufficient in advancing him to a level commensurate to his peer's. Furthermore, it did not produce intrinsic motivation to perform by completing missing assignments or maintaining homework compliance.

Student 5 failed to demonstrate improvement during treatment. His teacher attributed this to his inability to return his work on a regular basis and to return incomplete work. Student 5 was receiving a failing grade at the end of treatment, and his average completion and accuracy rates had decreased.

Although at follow-up the performance of Student 5 continued to be variable, his grade had increased to a "C." When contacted, his mother indicated that she had implemented a structured homework routine and that she made conscientious attempts to supervise or check his work nightly. Presumably, many of the intervention components established during consultation were being implemented at follow-up (i.e., a homework schedule and positive reinforcement). In some ways, this is reflective of generalization effects over time (i.e., his mother independently chose to use the knowledge about homework structure and programming gained during $\mathrm{CBC}$ at a later time).

\section{Research Strengths and Contributions}

In this study there was simultaneous attention afforded to both process (CBC) and content (homework intervention) issues. Although previous authors have limited their investigations to either process or content elements of an intervention, both are operative in actual practice. This dual focus allowed for a closer approximation of the realities facing field-based scientist practitioners, and is considered an important research strength.

Second, this study contributed to the small but growing body of CBC research, and is the first to target junior high school students. In fact, there are very few consultation studies targeting this population. Relatedly, it is one of the few studies that incorporates the client (i.e., student) into the consultation process.

A third strength of the study was the experimental design (i.e., multiple baseline design across five participants). The multiple baseline design provided opportunity to control for internal threats to validity (e.g., maturation, history, attrition, etc.). In an extensive review, Sheridan, Welch, and Orme (1996) identified the need for more single subject experimental studies in consultation. Fourth, the study used permanent products as a measure of intervention effectiveness. Permanent products 
tend to be highly objective, and the use of permanent products in this study provided tangible evidence of completion and accuracy before, during, and after treatment.

Fifth, the present study included several measures to corroborate treatment effects as recommended by Sheridan, Welch, \& Orme (1996). These include measures of integrity, acceptability, and social validity. The treatment integrity measures assessed the integrity of both the consultation process and the intervention procedures. Treatment acceptability measures were included that assessed consumer satisfaction with the consultation process and the intervention procedures. Finally, social validity measures helped to determine the social relevancy of the changes to the students participating in the study.

\section{Research Limitations}

One limitation of this study was the lack of stability and the large range of data points in baseline. The criteria for selection and analysis of participants' behaviors prior to treatment implied that their behaviors would be extremely variable regarding homework completion and accuracy. This made extending baseline until stability was achieved inappropriate, since it was unlikely that baseline would ever become stable. In addition, a "retrospective baseline" provided by teacher inspection of existing records (i.e., grade books) yielded highly similar (i.e., variable) patterns in student performances over an extended period.

Second, due to scheduling difficulties, the initiation of treatment for Students 1 and 2 did not occur simultaneously, and this resulted in an unintended, nonexperimental lag across these two students. Notably, this design issue precludes the interpretation of experimental control across Students 1 and 2, and across Students 2 and 3. It should be recognized, however, that the original student pairing design did not call for a lag between Students 1 and 2. Further, an interpretation may be possible for treatment effects demonstrated by Student 1 while Student 3 remained in a baseline control condition, particularly given the immediate effects observed with the introduction of treatment for Student 3.

Third, treatment integrity data were available for only two participants. This makes it difficult to attribute behavioral change to the intervention. It was unclear whether these parents implemented the intervention as intended. The parent of Student 5 revealed that she did not provide treatment on at least $30 \%$ of the treatment days. However, it is unclear whether she complied with treatment the remaining days. It is noteworthy that at follow-up, a partially structured homework program was in place for this student, and although his performance was variable his grade increased to passing. Alternatively, the parent of Student 2 withdrew treatment components at home when consultation ended, and this student failed to maintain the positive gains he demonstrated during treatment.

A related integrity issue is that neither time spent doing homework nor homework supervision were assessed directly. Rather, self-reports, in the form of treatment integrity checklists, were used. Indeed, the degree to which results can be attributed to the intervention package is contingent upon acceptable levels of in- tervention integrity, a concept receiving attention in the consultation literature (e.g., Witt, Gresham, \& Noell, 1996).

Fourth, the only measures used to assess satisfaction were self-reports. No respondents were blind to the procedures, and responses may have been reflective of a social desirability response set. The potential for this type of bias in responding seems most evident for teacher and parent consultees, who tended to respond toward the high (desirable) end of the satisfaction scales, compared to students who responded in a more neutral manner.

Fifth, homework assignments were not standardized. Rather, they reflected "normal" homework provided by teachers, and there may have been inconsistencies across assignments and teachers. Attempts were made to control the length of time required to complete the assignments, but that was left to the teachers' discretion and not evaluated objectively.

Finally, as a comprehensive treatment package including both process and content elements, it is impossible to identify which separate or combined components served as the "active ingredient" to facilitate change. In other words, it is not possible to separate out the components or subcomponents of the intervention package that accounted for the results. It must be recognized that neither CBC nor the behavioral homework intervention can be identified in isolation as producing the observed effects. Future $\mathrm{CBC}$ research may investigate more directly the unique contributions of process and content elements, while also recognizing the importance of both in field-based practice.

\section{SUMMARY}

The $\mathrm{CBC} /$ homework program used in this study appears to have promise for school psychologists or other professionals trained in behavioral consultation procedures to be used with parents, teachers, and junior high students exhibiting difficulties with their math homework. This study demonstrated that the procedures were effective, and both the consultation process and the intervention were acceptable to consumers. This study also supported the assumption that parents of older children want to be involved with their child's education (Epstein \& Connors, 1992). All of the parents participating in this study were concerned with their child's performance in math, and were willing to expend personal resources (time and reinforcers) to benefit their child. $\mathrm{CBC}$ is one procedure that may establish critical links between the home and school experiences of middle school students. Indeed, it shows promise as an aide to parents interested in maximizing out-ofschool time, and structuring the home environment to support school learning.

\section{REFERENCES}

Anesko, K. M., \& Levine, F. M. (1987). Winning the homework war. New York: Simon \& Schuster.

Bergan, J. R., \& Kratochwill, T. R. (1990). Behavioral consultation and therapy. New York Plenum. 
Bronfenbrenner, U. (1977). Toward an experimental ecology of human development. American Psychologist. 32, 513-529.

Busk, P. L., \& Serlin, R. C. (1992). Meta-analysis for single-case research. In T. R. Kratochwil \& J. R. Levin (Eds.), Single case research design and analysis: Applications in psychology and education (pp. 187-212). Hillsdale, NJ: Erlbaum.

Canter, L., \& Hausner, D. (1987). Homework without tears: A parent guide for motivating children to do homework and succeed in school. New York: Harper and Row.

Christenson, S. L., \& Cleary, M. (1990). Consultation and the parent-educator partnership: A perspective. Journal of Educational and Psychological Consultation, 1, 219-241.

Christenson, S. L., Rounds, T., \& Franklin, M. J. (1992). Home-school collaboration: Effects, issues, and opportunities. In S. L. Christenson \& J. C. Conoley (Eds.), Home-school collaboration: Enhancing children's academic and social competence (pp. 19-51). Silver Spring, MD: National Association of School Psychologists.

Clark, R. M. (1983). Family life and school achievement. Chicago: University of Chicago Press.

Comer, J. P., \& Haynes, N. M. (1991). Parent involvement in schools: An ecological approach. The Elementary School Journal, 91, 271-277.

Elliott, S. N.,\& Von Brock Treuting, M. (1991). The Behavior Intervention Rating Scale: Development and validation of a pretreatment acceptability and effectiveness measure. Journal of School Psychology, 29, 43-51.

Epstein, J. L. (1987). Toward a theory of home-school connections: Teacher practices and parent involvement. In K. Hurrelmann. F. Kaufmann, \& F. Losel (Eds.), Social intervention: Potential and constraints (pp. 121-136). New York: deGruyter

Epstein, J. L., \& Connors, L. J. (1995). School and family partnerships in the middle grades. In B. Rutherford (Ed), Creating school-family partnerships (pp. 137-166). Columbus, OH: National Middle School Association.

Erchul, W. P. (1987). A relational communication analysis of control in school consultation. Professional School Psychology, 2, 113-124.

Erchul, W. P., \& Chewning, T. G. (1990). Behavioral consultation from a request-centered relational communication perspective. School Psychology Quarterly, 5, 1-20.

Fish, M. C., \& Mendola, L. R. (1986). The effect of self-instruction training on homework completion in an elementary special education class. School Psychology Review, 15, 268-276.

Galloway, J., \& Sheridan, S. M. (1994). Implementing scientific practices through case studies: Examples using home-school interventions and consultation. Journal of School Psychology, $32,385-413$.

Greenwood, G. E., \& Hickman, C. W. (1991). Research and practice in parent involvement: Implications for teacher education. The Elementary School Journal, 97, 279-288.

Gresham, F. M., \& Noell, G. H. (1993). Documenting the effectiveness of consultation outcomes. In J. E. Zins, T. R. Kratochwill, \& S. N. Elliott (Eds.), Handbook of consultation services for children (pp. 249-273). San Francisco: Jossey-Bass Publishers.

Hart, D., \& Rechif, M. (1986). Mind movers: Creative homework assignments-Grades 3-6. Reading, MA: Addison-Wesley.

Hoover-Dempsey, K. V., Bassler, 0. C., \& Brissie, J. S. (1987). Parent involvement: Contribution of teacher efficacy, social socioeconomic status, and other characteristics. American Educational Research Journal, 24, 417-435.

Kazdin, A. E. (1977). Assessing the clinical or applied importance of behavior change through social validation. Behavior Modification, I, 427-451.

Keith, T. (1986). Homework. West Lafayette, IN: Kappa Delta Pi Publications.

Kratochwill, T. R. (1985). Case study research in school psychology. School Psychology Review, 14, 204-215.

Kratochwill, T. R., \& Bergan, J. R. (1990). Behavioral consultation in applied settings. New York: Plenum.
Kuepper, J. E. (1987). Homework helpers: A guide for parents offering assistance. Minneapolis, MN: Educational Media.

Malyn, D. (1985). Use of chart moves and spinners with homework compliance. Unpublished master's thesis, University of Utah, Salt Lake City, UT.

Miller, D. L., \& Kelly, M. L. (1994). The use of goal setting and contingency contracting for improving children's homework performance. Journal of Applied Behavior Analysis, 27, $73-84$.

Moore, L. A., Waguespack, A. M., Wickstrom, K. F., Witt, J. C-, \& Gaydos, G. R. (1994). Mystery motivator: An effective and time efficient intervention. School Psychology Review, 23, $106-118$.

Olympia, D. E., Jenson, W. R., \& Hepworth-Neville, M. (1996). Sanity savers for parents: Tips for tackling homework. Longmont, CO: Sopris-West.

Olympia, D. E., Sheridan, S. M., \& Jenson, W. R. (1994). Homework: A natural means of homeschool collaboration. School Psychology Quarterly, 9, 60-80.

Olympia, D. E., Sheridan, S. M., Jenson, W., \& Andrews, D. (1994). Using student-managed interventions to increase homework completion and accuracy. Journal of Applied Behavior Analysis, 27, 60-80

Rhode, G., Jenson, W. R., \& Reavis, H. K. (1992). The tough kid book. Longmont, CO: Sopris West, Inc.

Scruggs, T. E., Mastropieri, A. M., \& Casto, G. (1987). The quantitative synthesis of single-subject research: Methodology and validation. Remedial and Special Education, 8, 24-33.

Sheridan, S. M. (1997). Conceptual and empirical bases of conjoint behavioral consultation. School Psychology Quarterly, 12, 119-133.

Sheridan, S. M., \& Kratochwill, T. R. (1992). Behavioral parent-teacher consultation: Conceptual and research considerations. Journal of School Psychology, 30, 117-139.

Sheridan, S. M., Kratochwill, T. R., \& Bergan, J. R. (1996). Conjoint behavioral consultation: A procedural manual. New York: Plenum.

Sheridan, S. M., \& Steck, M. (1995). Acceptability of conjoint behavioral consultation: A national survey of school psychologists. School Psychology Review, 24, 633-647.

Sheridan, S. M., Welch, M., \& Orme, S. (1996). Is consultation effective? A review of outcome research. Remedial and Special Education, 17, 341-354.

Tawney, J. W., \& Gast, D. L. (1984). Single-subject research in special education. Columbus, OH: Charles E. Merrill.

Von Brock, M. B., \& Elliott, S. N. (1987). Influence of treatment effectiveness information on the acceptability of classroom interventions. Journal of School Psychology, 25, 131-144.

Witt, J. C., \& Elliott, S. N. (1985). Acceptability of classroom management strategies. In T. R Kratochwill (Ed.), Advances in school psychology (Vol. 4, pp. 251 -288). Hillsdale, NJ: Erlbaum.

Witt, J. C., Gresham, F. M., \& Noell, G. H. (1996). What's behavioral about behavioral consultation? Journal of Educational and Psychological Consultation, 7, 327-344.

$\S \S \S \S$

The "Action Editor" for School Psychology Quarterly was Terry B. Gutkin. This paper was accepted September 2, 1998 